\title{
PENGEMBANGAN KURIKULUM SEKOLAH BERTARAF INTERNASIONAL
}

Sri Purnami

Dosen UIN Sunan Kalijaga Yogyakarta

\begin{abstract}
Development of the connectedness of the world affects the lives of individuals and national institutions. This has prompted the government to develop international education by starting with the pioneering on international standard schools (Rintisan Sekolah Bertaraf International-RSBI) model. The implementation of international standard schools based on the philosophy of existentialism and essentialism / functionalism. RSBI is ordered by the government to adopt the curriculum of one of the OECD countries, that are countries considered to have been developed and established, to be implemented at the school. One of them is a popular Cambridge International Education (CIE), which originated in England. Students will be free how they will learn, how long a period of time, and others. Students may learn at school / educational institutes, self-taught, taught by the parents themselves, tutorials, or private.
\end{abstract}

Keywords: Curriculum development and RSBI

\section{Pendahuluan}

Saat ini kita sudah memasuki era globalisasi. Globalisasi menurut Giddens adalah meningkatnya relasi sosial tingkat dunia yang menghubungkan berbagai wilayah yang jauh sedemikan rupa sehingga peristiwa lokal bisa dipengaruhi oleh peristiwa yang terjadi bermilmil jauhnya dan sebaliknya. Selanjutnya, Reeves (1995) menyatakan bahwa perkembangan keterhubungan tingkat dunia ini mempengaruhi institusi nasional maupun kehidupan individu. Skala baru perdagangan internasional, sistem keuangan dunia, dan aktivitas perusahaan transnasional, produksi dan diseminasi pengetahuan yang mendunia, mobilitas 


\section{Sri Purnami}

buruh, fasilitas transportasi dan perjalanan, jaringan media dan komunikasi, bahasa, sejarah, etnisitas, dan agama dari negara yang berbeda-beda, dan pertumbuhan dan perkembangan organisasi politik supra-nasional, menjadi dasar untuk mengklaim bahwa tatanan dunia baru atau masyarakat dunia baru telah muncul.

Dengan asumsi bahwa sumber daya yang dimiliki bumi kita terbatas, maka implikasi lebih jauh akibat globalisasi tersebut adalah terjadinya persaingan yang semakin ketat. Agar tetap bisa survive, memiliki keunggulan untuk dapat berkompetisi secara global adalah sesuatu yang tak terelakkan. Kemampuan untuk dapat bersaing secara global ini terutama diperoleh melalui jalur pendidikan. Oleh pemerintah, hal ini sudah diantisipasi tercermin dalam UU RI No. 20 tentang Sisdiknas Pasal 50 ayat 3 yang berbunyi: "Pemerintah dan/atau pemerintah daerah menyelenggarakan sekurang-kurangnya satu satuan pendidikan untuk dikembangkan menjadi satuan pendidikan yang bertaraf internasional".

Amanat undang-undang tersebut ditafsirkan oleh Kementrian Pendidikan Nasional dengan mengeluarkan kebijakan untuk menyelenggarakan Sekolah Bertaraf Internasional (SBI). Proyek rintisan ini menyertakan ratusan SMP dan SMA di hampir semua Kabupaten/ Kota di Indonesia dengan menggelontorkan dana ratusan milyar. Sampai pada tahun 2009, tercatat jumlah sekolah yang diikutsertakan untuk tingkat SD 195 sekolah, SMP 299 sekolah, SMA 321 sekolah dan SMK 295 sekolah. Dalam pelaksanaannya, alih-alih membantu memecahkan problem pendidikan nasional, keberadaan SBI justru menimbulkan masalah baru. SBI menuai banyak kritik, karena konsepnya tidak jelas, penyelenggaraannya yang melenceng dari konsep awal, dan dampak yang ditimbulkannya. Contoh dari hal tersebut sekolah memungut dana yang tinggi sehingga hanya siswa dari kalangan 'atas' yang mampu memasukinya.

Contoh lain, konsep SBI harus menggunakan bahasa Inggris untuk mengajar di kelas. Sebenarnya konsep ini maksudnya baik agar siswa terbiasa berkomunikasi dengan bahasa global, tetapi penelitian Suharyadi (2010) menunjukkan bahwa pola komunikasi di kelas hanya guru saja yang aktif berbahasa Inggris. Selain itu ternyata kebanyakan siswa lebih memahami materi, jika diajarkan dengan bahasa Indonesia. Pada pelajaran 
matematika $85 \%$ siswa menyatakan demikian, $100 \%$ pada mata pelajaran biologi dan 77, $77 \%$ pada mata pelajaran bahasa Inggris. Puncak dari persoalan tersebut adalah adanya desakan dari masyarakat dan DPR untuk menghentikan SBI/RSBI. Pemerintah pun merespon desakan tersebut dengan menghentikan sementara pemberian izin baru RSBI mulai tahun 2011 dan mengevaluasi sekolah-sekolah yang berstatus RSBI.

\section{Konsep SBI Versi Pemerintah}

Menurut Ditjen Kemendiknas, pendidikan bertaraf internasional adalah pendidikan yang diselenggarakan setelah memenuhi Standar Nasional Pendidikan (SNP) dan diperkaya dengan standar pendidikan dari negara maju. Hal ini menjadi acuan mutu pendidikan untuk meningkatkan kualitas dan daya saing baik di tingkat regional maupun internasional, serta peningkatan dan pemerataan mutu pendidikan. Secara matematis SBI dirumuskan sebagai berikut:

$$
\mathbf{S B I}=\mathbf{S N P}+\mathbf{X}
$$

SNP adalah Standar Nasional Pendidikan yang meliputi standar isi, proses, kompetensi lulusan, pendidik dan tenaga kependidikan, sarana dan prasarana, pengelolaan, pembiayaan, dan penilaian pendidikan. Sedangkan $\mathrm{X}$ adalah penguatan, pengayaan, pengembangan, perluasan, pendalaman melalui adaptasi atau adopsi terhadap standar pendidikan, baik dari dalam maupun luar negeri yang diyakini telah memiliki reputasi mutu yang diakui secara internasional.

Latar belakang pendirian sekolah berstandar internasional adalah:

- Pada tahun 90-an banyak sekolah yang didirikan oleh suatu yayasan dengan menggunakan identitas internasional, tetapi tidak jelas kualitas dan standarnya,

- Banyak orang tua yang mampu secara ekonomi memilih menyekolah kan anaknya ke luar negeri,

- Belum ada payung hukum yang mengatur penyelenggaraan sekolah internasional,

- Perlunya membangun sekolah berkualitas sebagai pusat unggulan (center of excellence) pendidikan, 


\section{Sri Purnami}

- Atas fenomena di atas, pemerintah mulai mengatur dan merintis sekolah bertaraf internasional, dan

- Sebagai bangsa yang besar, Indonesia perlu pengakuan secara internasional terhadap kualitas proses, dan hasil pendidikannya.

Selanjutnya, untuk disebut sebagai sekolah berstandar internasional, maka harus memiliki kriteria sebagai berikut:

\begin{tabular}{|c|c|}
\hline Parameter & Persyaratan \\
\hline SNP & Harus sudah terpenuhi. \\
\hline Guru & $\begin{array}{l}\text { Min. S2/S3: } 10 \% \text { (SD), } 20 \% \text { (SMP), } 30 \% \\
\text { (SMA/K). }\end{array}$ \\
\hline Kepala Sekolah & Min. S2 dan mampu berbahasa asing secara aktif. \\
\hline Akreditasi & $A(95)$. \\
\hline Sarana prasarana & Berbasis TIK. \\
\hline Kurikulum & $\begin{array}{l}\text { KTSP diperkaya dengan kurikulum dari negara } \\
\text { maju, penerapan SKS pada SMA/K. }\end{array}$ \\
\hline Pembelajaran & $\begin{array}{l}\text { Berbasis TIK dan bilingual (mulai dari kelas } 4 \text { SD), } \\
\text { sister school dengan sekolah dari negara maju. }\end{array}$ \\
\hline Manajemen & Berbasis TIK, ISO 9001 dan ISO 14000. \\
\hline Evaluasi & $\begin{array}{l}\text { Menerapkan model UN dan diperkaya dengan } \\
\text { sistem ujian internasional negara maju atau } \\
\text { negara lain yang memiliki keunggulan tertentu. }\end{array}$ \\
\hline Lulusan & $\begin{array}{l}\text { Memiliki daya saing internasional dalam } \\
\text { melanjutkan pendidikan dan bekerja (SMK). }\end{array}$ \\
\hline Kultur sekolah & $\begin{array}{l}\text { Terjaminnya pendidikan karakter, bebas bullying, } \\
\text { demokratis, dan partisipatif. }\end{array}$ \\
\hline Pembiayaan & $\begin{array}{l}\text { APBN, APBD, dan boleh memungut biaya dari } \\
\text { masyarakat atas dasar RAPBS yang akuntabel; } \\
\text { minimal } 20 \% \text { peserta didik tidak mampu } \\
\text { mendapatkan subsidi pendidikan. }\end{array}$ \\
\hline
\end{tabular}


Penyelenggaraan sekolah berstandar internasional didasarkan oleh filosofi eksistensialisme dan esensialisme / fungsionalisme .

Eksistensialisme menekankan bahwa pendidikan harus menyuburkan dan mengembangkan eksistensi peserta didik seoptimal mungkin melalui fasilitasi yang dilaksanakan melalui proses pendidikan yang bermartabat, pro perubahan (kreatif, inovatif dan eksperimentatif), menumbuhkan dan mengembangkan bakat, minat dan kemampuan peserta didik. Sedangkan, esensialisme/ fungsionalisme menekankan bahwa pendidikan harus berfungsi dan relevan dengan kebutuhan, baik kebutuhan individu, keluarga, maupun kebutuhan berbagai sektor dan sub-subsektornya, baik lokal, nasional maupun internasional.

Terkait dengan kurikulum, RSBI ditugaskan oleh pemerintah untuk mengadopsi kurikulum dari salah satu negara OECD, yaitu negara-negara yang dianggap sudah maju dan mapan, untuk diterapkan di sekolah tersebut. Salah satunya yang populer adalah Cambridge International Education (CIE) yang berasal dari Inggris. CIE pada prinsipnya mirip TOEFL. Siswa dibebaskan bagaimana mereka akan belajar, berapa lama jangka waktunya, dan lain-lain. Siswa boleh belajar di sekolah/lembaga pendidikan, otodidak, diajar orang tua sendiri, tutorial, atau privat. Jangka waktu yang diperlukan umumnya antara 1 sampai 3 tahun. Hal yang terpenting dari keseluruhan cara tersebut adalah mereka lulus pada saat ujian yang dilaksanakan serentak di seluruh dunia. Jika mereka lulus akan mendapat sertifikat yang menjelaskan kelulusan mereka pada mata pelajaran apa dan dengan tingkat apa, misalnya matematika grade $B$, Fisika grade D, dan seterusnya. Hanya siswa yang lulus pada mata pelajaran tersebut yang mendapat sertifikat.

Perbedaan dengan sistem TOEFL (dan Ujian Nasional kita) adalah tingkat detail kejelasan mengenai apa yang akan diujikan. Istilah yang digunakan unuk mata pelajaran adalah "silabus". Silabus dipublikasikan tiga tahun sebelum ujian dilaksanakan. Sedangkan, normalnya waktu untuk belajar menghadapi ujian adalah dua tahun pembelajaran untuk sistem sekolah klasikal. Ini berarti pendidik memiliki waktu satu tahun untuk memikirkan bagaimana menyampaikan silabus tersebut dalam kelas. Silabus mencakup daftar apa saja yang diharapkan akan dikuasai dan akan diujikan. Tidak semua materi dalam silabus akan keluar dalam 
ujian, namun tidak akan ada materi yang diujikan tidak tercantum dalam silabus.

\section{Perspektif Pengembangan Kurikulum}

Pengertian Kurikulum

Kurikulum merupakan kunci utama sekolah saat ini. Oleh karena itu, pembahasan tentang penyelenggaraan suatu sekolah akan sangat relevan jika dikaitkan dengan konsep pengembangan kurikulum. Menurut Oliva (1992), kurikulum adalah sebuah rancangan atau program bagi semua pengalaman yang akan dimasuki pembelajar di bawah arahan sekolah. Dalam praktek, kurikulum terdiri dari sejumlah rencana dalam bentuk tertulis dan cakupan yang bervariasi, yang menjelaskan pengalaman belajar yang diinginkan. Oleh karena itu, kurikulum dapat berupa satu unit, satu mata pelajaran, serangkaian mata pelajaran, maupun program pelajaran sekolah secara keseluruhan dan dapat terjadi di luar kelas atau sekolah ketika dipandu oleh personil sekolah.

Pengertian lain tentang kurikulum dikemukakan oleh Doll (1992) bahwa kurikulum sekolah adalah isi dan proses secara formal maupun informal yang dengan itu pembelajar memperoleh pengetahuan dan pemahaman, mengembangkan ketrampilan, mengubah sikap, apresiasi dan nilai-nilai dengan pihak bantuan sekolah. Dari kedua definisi tersebut dapat disimpulkan bahwa kurikulum pada hakekatnya adalah pengalaman belajar siswa yang diperoleh baik secara formal maupun informal di sekolah sehingga siswa memperoleh pengetahuan dan pemahaman, ketrampilan, sikap, apresiasi dan nilai-nilai dengan bantuan sekolah.

Pengertian kurikulum perlu dibedakan dengan instruction (pengajaran). Kurikulum dapat dipandang sebagai "apa" dan pengajaran sebagai "bagaimana" (Oliva, 1992). Lebih lanjut, Oliva menyatakan bahwa dalam merencanakan kurikulum atau pengajaran, keputusan harus dibuat. Keputusan tentang kurikulum berkaitan dengan rencana atau program sehingga bersifat programatik. Sedang pengajaran (dan implementasinya) bersifat metodologis. Baik kurikulum maupun pengajaran merupakan bagian dari sistem yang lebih besar yang disebut persekolahan atau pendidikan. 
Berdasar konsep 'pengertian kurikulum' ini, terlihat ada kesenjangan antara kurikulum SBI yang diadopsi dengan pengertian kurikulum itu sendiri. Secara konseptual, pengertian kurikulum menekankan bahwa terjadinya pengalaman belajar pada diri siswa terjadi dengan bantuan pihak sekolah. Sedang kurikulum SBI yang diadopsi, yaitu Cambridge International Education (CIE) membebaskan siswanya untuk memperoleh pengalaman belajar di mana saja, bisa dari sekolah, diajar sendiri oleh orang tua, les privat, tutorial, dan lain-lain. Sebab yang terpenting adalah bisa mengikuti ujian yang telah ditetapkan. Pengalaman belajar di sekolah hanya salah satu cara saja. Terlebih dikemukakan diatas bahwa CIE ini lebih mirip TOEFL.

Dengan demikian, kurikulum CIE ini tampaknya tidak dirancang khusus untuk kurikulum sekolah. Oleh karena itu, masih bisa dipertanyakan apakah kurikulum CIE yang diadopsi ini sebenarnya kurikulum untuk pendidikan di sekolah atau kurikulum untuk lembaga kursus seperti halnya kursus-kursus bimbingan belajar yang menjamur di negara kita. Perbedaannya, kalau lembaga bimbingan belajar negara kita berorientasi pada kemampuan untuk bisa menembus ujian masuk Perguruan Tinggi Negeri atau PT favorit, sedang CIE berorientasi pada PT luar negeri.

\section{Prinsip-Prinsip Pengembangan Kurikulum}

Oliva (1992) merumuskan sepuluh prinsip pengembangan kurikulum. Kesepuluh prinsip tersebut - yang oleh Oliva disebut aksioma - adalah:

- Inevitability of change

Berdasar prinsip ini, konsep SBI yang secara sistematis adalah SBI $=\mathrm{SNP}+\mathrm{X}$ mengindikasikan pandangan bahwa kurikulum nasional pendidikan kita seakan-akan sudah "selesai" atau sudah sampai pada titik puncak dan tidak perlu direvisi lagi. Padahal dengan menggunakan prinsip ini, sebenarnya memungkinkan terjadinya perubahan SNP (kurikulum) menuju ke arah yang lebih ideal lagi yang sesuai dengan kebutuhan jaman. Jika sekarang globalisasi sudah tak terelakkan lagi mengapa masih harus menggunakan kurikulum yang tidak menghasilkan lulusan yang mampu berkompetisi secara global? Dengan kata lain, mengadopsi kurikulum negara lain agar mampu 
menghasilkan lulusan yang mampu bersaing secara global bukanlah keputusan yang bijak.

- Curriculum as a product of time

Turney berpendapat dibutuhkan sekurang-kurangnya satu abad untuk terjadinya perubahan dasar. Ada juga yang berpendapat bahwa untuk melihat pengaruh inovasi kurikulum diperlukan waktu 50 tahun, dan untuk bisa diadopsi secara universal oleh sekolah-sekolah dibutuhkan 50 tahun tambahan. Namun demikian Oliva mengingatkan inovasi kurikulum mungkin tidak perlu membutuhkan waktu 50 hingga 100 tahun. Boleh jadi hanya membutuhkan tiga, lima, sepuluh tahun, atau lebih sebelum dipraktekkan secara umum.

Kaitannya dengan SBI, mengadopsi begitu saja kurikulum dari negara lain bukanlah keputusan yang bijak. Ini sebab tidak akan bisa memenuhi semua kebutuhan masyarakat Indonesia. Kurikulum yang diadopsi dari luar negeri merupakan hasil dari perjalanan sejarah panjang negeri yang bersangkutan, dengan segala macam karakteristik dan keunikan tersendiri yang tentunya berbeda dengan sejarah negeri kita sendiri. Kurikulum adalah produk dan sekaligus bagian dari sejarah masyarakat tertentu.

- Concurrent changes

Prinsip ini menjelaskan bahwa perubahan kurikulum yang dibuat pada periode waktu sebelumnya dapat eksis seiring sejalan dengan perubahan kurikulum yang lebih baru pada periode waktu sesudahnya. Dengan prinsip ini, konsep SBI $=$ SNP + X mengindikasikan bahwa posisi kurikulum nasional kita lebih rendah daripada kurikulum internasional. Pemerintah menunjukkan rasa tidak percaya dirinya bahwa kurikulum nasional kita lebih jelek oleh karena itu harus diberi "plus" agar bisa menjadi lebih baik.

- Change in people

Perubahan kurikulum merupakan hasil dari perubahan pada diri orang. Jadi pengembang kurikulum harus berusaha untuk mengubah orang lebih dulu yang pada akhirnya mempengaruhi perubahan kurikulum. Program SBI adalah kebijakan dari atas / top down yang tercermin dari UU RI No. 20 tentang Sisdiknas Pasal 50 ayat 3 yang berbunyi: "Pemerintah dan / atau pemerintah daerah menyelenggarakan sekurang- 
kurangnya satu satuan pendidikan untuk dikembangkan menjadi satuan pendidikan yang bertaraf internasional" Pasal ini jelas bisa dimaknai bahwa inisiatif adanya SBI adalah dari pemerintah baik pusat maupun daerah.

- Cooperative endeavor

Perubahan kurikulum terjadi sebagai hasil pendekatan kerjasama antar bagian kelompok. Perkembangan kurikulum lebih sebagai pertumbuhan individu daripada sebagai pemasangan atau konstruksi materi tertentu. Oleh karena itu, semakin individu bisa mengidentifikasi diri dengan aktivitas kurikulum, maka semakin siap menerima fase baru. Prinsip ini juga tidak diterapkan dengan baik dalam membentuk SBI. SBI lebih menekankan adopsi kurikulum luar negeri. Ini adalah bentuk dari pemasangan atau konstruksi materi tertentu.

- Decision making process

Pengembangan kurikulum pada dasarnya merupakan proses pengambilan keputusan. Pilihan-pilihan yang harus dibuat adalah mata pelajaran yang akan diberikan, cara pandang yang akan dianut, penekanan yang harus dilakukan, metode yang perlu dilaksanakan, dan pilihan bagaimana mengorganisasikannya. Berbagai protes dan kritik yang muncul sebagai akibat dari dampak yang ditimbulkan dalam penyelenggaraan SBI menunjukkan bahwa pengambil keputusan belum memperhitungkan secara baik pilihan yang diambil. Ini misal kebijakan penggunaan bahasa Inggris sebagai bahasa pengantar di kelas ternyata justru membuat siswa kesulitan menguasai materi.

- Continuous processng

Pengembangan kurikulum merupakan proses yang tidak pernah berhenti. Pengembang kurikulum harus secara terus menerus berjuang mencari kurikulum yang ideal. Prinsip ini mengisyaratkan bahwa kurikulum nasional pendidikan kita yang terjabarkan dalam SNP tetap harus dikembangkan. Sebagaimana yang telah dipaparkan pada prinsip pertama di atas, maka sebenarnya tidak perlu memisahkan antara kurikulum berstandar nasional dan internasional jika pada akhirnya masyarakat kita mau tidak mau dihadapkan pada kenyataan adanya pengaruh globalisasi. Kita semua akan menuju ke sana, hanya persoalan waktu yang membedakan, ada yang cepat dan yang lambat. 


\section{Sri Purnami}

- Comprehensive process

Pengembangan kurikulum merupakan proses yang komprehensif. Perencanaan kurikulum sering terlalu lebih menekankan bagian-bagian (sistem tambal sulam) daripada secara holistik atau komprehensif. Pendekatan yang komprehensif menuntut investasi sumber daya fisik dan manusia yang besar. Konsep SBI = SNP + X menunjukkan secara jelas proses tambal sulam itu. Pemerintah mengira dengan menambah faktor "X" maka persoalan bagaimana membentuk satuan pendidikan bertaraf internasional sudah selesai. Padahal sebenarnya diperlukan persiapan yang betul-betul matang. Pada tataran di lapangan bisa kita lihat fenomena "tambal sulam" itu dengan disewanya dosen yang fasih berbahasa Inggris untuk mengajar di kelas karena gurunya tidak mampu melakukan itu. Juga persyaratan guru yang mengajar hard science harus memiliki skor TOEFL di atas 500.

- Systematic development

Pengembangan kurikulum yang sistematik lebih efektif daripada trial dan error. Pengembangan kurikulum idealnya harus dibuat secara komprehensif dengan mengikuti seperangkat prosedur yang telah ditetapkan. Seperangkat prosedur tersebut harus disetujui dan diketahui oleh semua yang berpartisipasi dalam pengembangan kurikulum. Dengan prinsip ini jelas mensyaratkan agar penyelenggaraan SBI dipersiapkan betul secara matang dan sistematis dengan seperangkat prosedur tertentu. Ini pun juga harus disetujui dan diketahui oleh semua pihak yang terlibat, baik level atas maupun bawah. Fenomena di lapangan menunjukkan hal yang sebaliknya.

- Starting from the existing curriculum

Pengembangan kurikulum harus berawal dari kurikulum yang sudah ada. Pengembangan kurikulum tidak terjadi secara singkat dalam waktu satu malam. Oleh karena itu, akan lebih tepat jika mereorganisasi kurikulum daripada membuat organisasi kurikulum yang baru.

Berdasar prinsip ini, maka sebenarnya lebih tepat jika kurikulum untuk SBI adalah reorganisasi dari kurikulum nasional pendidikan kita sendiri. Pengaruh globalisasi sudah merambah ke pelosok negeri baik terhadap lembaga negara maupun kehidupan individu. Masyarakat Indonesia harus segera dipersiapkan untuk mampu merespon dan 
beradaptasi dengan hal tersebut. Persiapan itu tentu saja hanya bisa dicapai melalui pendidikan. Secara lebih khusus dijabarkan dalam kurikulum (pengalaman belajar) yang memang sudah dirancang untuk itu. Oleh karena itu tidak perlu ada lagi dikotomi antara kurikulum nasional yang dijabarkan dalam SNP dengan kurikulum berstandar internasional.

\section{Filosofi Pendidikan}

Pengembangan kurikulum tidak bisa lepas dari filosofi pendidikan. Menurut Ornstein, dkk (2003), isu-isu filosofis selalu dan masih mempengaruhi sekolah dan masyarakat. Masyarakat kontemporer dan sekolah didalamnya berubah secara lebih mendasar dan lebih cepat daripada masa lalu. Oleh karena itu, menjadi kebutuhan yang mendesak untuk terus menerus menilai peran sekolah. Hal ini memerlukan filosofi pendidikan.

Secara garis besar ada empat filosofi pendidikan utama yang mempengaruhi pengembangan kurikulum, yaitu perenialisme, esensialisme, progresivisme, dan rekonstruksionisme (Oliva, 1992; Ornstein, dkk, 2003). Perenialisme meyakini bahwa kebenaran bersifat abadi, tak pernah berubah. Pendidikan bertujuan untuk mendidik pribadi yang rasional dan menanamkan intelektual. Pengetahuan yang dipelajari berfokus pada mata pelajaran masa lalu dan tetap, serta penguasaan fakta dan pengetahuan tanpa batas waktu.

Esensialisme memandang tujuan pendidikan secara umum adalah mentransmisikan warisan budaya. Tujuan pengajarannya meningkatkan perkembangan intelektual individu dan menjadikan individu memiliki kompetensi. Pengetahuan yang diajarkan mencakup ketrampilanketrampilan esensial dan akademik, serta penguasaan konsep-konsep dan prinsip-prinsip materi pelajaran. Guru memiliki otoritas dalam bidangnya. Juga mengajarkan nilai-nilai tradisional. Fokus kurikulum adalah ketrampilan esensial dan mata pelajaran dasar yaitu Bahasa Inggris, aritmetik, sains, sejarah dan bahasa asing.

Progresivisme disebut juga pragmatisme berpendapat bahwa sudah saatnya kita memposisikan materi pelajaran di bawah pembelajar. Pendidikan bukanlah produk yang harus dipelajari, misal fakta-fakta atau 
ketrampilan - tetapi merupakan proses yang terus menerus sepanjang hayat. Anak akan belajar dengan baik jika secara aktif mengalami dunianya sendiri. Jadi tidak secara pasif menyerap materi yang telah dipilihkan. Sekolah harus bisa menampung perbedaan individu dalam pengertian luas yang mencakup fisik, mental, emosi, spiritual, sosial dan kebudayaan.

Rekonstruksionisme berpendapat sekolah harusnya tidak hanya mentransmisikan warisan budaya atau semata-mata hanya mempelajari problem sosial. Sekolah harusnya juga bisa menjadi agen bagi pemecahan masalah sosial dan politik. Pelajaran yang diberikan harusnya yang problem-problem yang belum terpecahkan, sering bersifat kontroversial, misal pengangguran, kebutuhan akan kesehatan, perumahan, dan problem etnis. Konsensus kelompok merupakan metodologi yang digunakan untuk solusi masalah.

Beberapa filosofis di atas harus dipahami dengan baik oleh pengembang kurikulum. Dia harus tahu posisinya dimana, baik sebagai individu maupun sebagai kelompok dalam spektrum filosofis. Bisa jadi posisinya tersebut tidak murni mencerminkan satu macam filosofi. Filosofi pendidikan harus dinyatakan secara eksplisit dan koheren oleh sekolah yang bersangkutan. Filosofi tersebut merupakan hasil kerjasama antara guru dan karyawan, dan lebih baik lagi dengan orang tua dan siswa. Filosofi sekolah harus mencakup pernyataan keyakinan tentang tujuan pendidikan, masyarakat, siswa, dan peran guru (Oliva, 1992). Berikut ini adalah contoh filosofi sekolah yang dimaksud:

\section{STATEMENT OF PHILOSOPHY OF THE SCHOOL DISTRICT OF OMAHA}

The Board of Education of the Omaha Public School is responsible for meeting the challenge of providing a comprehensive educational program in atmosphere that is open, concerned, and responsive to the needs of students and the community. To this end, the Board of Education establishes policies that are translated into practices and procedures by the superintendent and staff to maintain and improve the quality of teaching and learning in Omaha Public Schools. The following statements express the philosophy that guided the school district in formation of its goals and objectives: 


\section{WE BELIEVE,}

- All students have an inherent right to an education that will enable them to reach their highest possible intelectual, social, physical, and ethical development.

- education must concentrate on the complete development of students as individuals and as citizens

- quallity education programs and a commited staff provide learners with the knowledge and skills necessary for full participation in our changing society

- the responsibility of education in a democracy is to make it possible for all citizens to understand themselves and the world about them, so that they can live effectively in the world of expanding experiences and constant change

- education requires systematic and sustained effort by students, staff, parents, and community.

- education is a life-long process (Oliva, 1992:210).

Saat ini penyelenggaraan SBI menggunakan filosofi eksistensialisme dan esensialisme. Merunut dari pengertian yang dijabarkan, filosofi eksistensialisme ini tampaknya dekat dengan filosofi progresivisme. Penggunaan filosofi ini pada dasarnya cukup baik. Ini dalam pengertian bahwa di satu sisi peserta didik diberi pengalaman belajar yang membuat mereka memiliki kompetensi tertentu, tetapi di sisi lain juga ada penghargaan terhadap keunikan individu yang beragam.

Hanya saja dalam praktek penyelenggaraan SBI/RSBI, implementasi filosofi ini belum optimal. Mestinya filosofi ini diimplementasikan secara nyata di sekolah, yaitu dengan dirumuskan dalam bentuk statemen yang jelas. Sekolah dan seluruh civitas yang ada di dalamnya harus punya perspektif dan keyakinan tertentu tentang apa itu pendidikan, apa tujuannya, bagaiman peran dan kedudukan siswa, guru, staf dan masyarakat dalam penyelenggaraan pendidikan di sekolah tersebut. Statemen ini tidak dimaksudkan untuk slogan atau hiasan dinding semata. Tapi juga harus dijadikan panduan dalam setiap langkah penyelenggaraan pendidikan di sekolah. 


\section{Penutup}

Sistem pendidikan yang menyiapkan peserta didik untuk mampu bersaing secara global tetap diperlukan. Sistem pendidikan tersebut tidak perlu menggunakan label "bertaraf internasional" sebab pada akhirnya kita semua akan menuju ke sana. Oleh karena itu, sistem pendidikan tersebut berlaku untuk semua peserta didik warga negara Indonesia. Kurikulum pendidikan untuk itu harus dipersiapkan secara matang, dan komprehensif dan perumusannya melibatkan semua pihak dengan menggunakan prinsipprinsip pengembangan kurikulum yang ada. Kurikulum yang disusun juga harus dilandasi oleh filosofi yang jelas dan eksplisit dinyatakan di setiap sekolah.

\section{Daftar Pustaka}

Depdiknas. (2007). Panduan Penyelenggaraan Rintisan Sekolah Bertaraf Internasional (SBI) Untuk SMP. Jakarta: Dirjen Manajemen Pendidikan Dasar dan Menengah. Direktorat Pembinaan Sekolah Menengah Pertama.

Direktorat Jendral Manajemen Pendidikan Dasar dan Menengah Kementrian Pendidikan Nasional. (t.t). dalam http:/www. mandiknasmen. depdiknas.go.id/docs/dok_34.pdf. Tanggal akses: 13 Maret 2011.

Doll, R.C. (1992). Curriculum Improvement. Decision Making and Process. 8th Ed. Boston: Allyn and Bacon.

Oliva, P.F. (1992). Developing The Curriculum. 3rd Ed. New York: Harper Collins Publishers.

Ornstein, A.C., Behar-Horenstein, L.S., \& Pajak, E.F. (2003). Contemporarry Issues in Currculum. 3rd Ed. Boston: Allyn and Bacon.

Reeves, F. (1995). The Modernity of Further Education. The Direction of Change in Further Education Colleges.Bilston England: Bilston College Publications in association with Education Now.

Rizali, A. (2008). Sekolah Bertaraf Internasional (SBI): Program Gagal?. dalam http:/ahmadrizali.com/index.php/2008/09/27/sekolah- 
bertaraf-internasional- sbi program-gagal/. Tanggal akses: 26 Maret 2010.

Satria Dharma. (2007). Sekolah Bertaraf Internasional: Quo Vadiz? dalam http://satriadharma.wordpress.com/2007/09/19/sekolah-bertarafinternasional-quo-vadiz/.

Syahreal Tjais. (2009) Mengenal Jenis Kurikulum Rintisan Sekolah Bertaraf Internasional (bagian 1). dalam $\mathrm{h} \mathrm{t} \mathrm{t} \mathrm{p}: / /$ e d u k a s i . kompasiana.com/2009/11/30/mengenal-jenis-kurikulum-sekolahbertaraf-internasional-bagian-1. Tgl akses 13 Maret 2011. 
Sri Purnami 